\title{
Voltage Sag and Swell compensation using DVR to enhance Power Quality
}

\author{
Suresh Palla ${ }^{1}$, Keerthi Sandela ${ }^{2}$, B. Sai Ramya ${ }^{3}$ \\ ${ }^{I}$ (Electrical and Electronics Engineering, .G.Narayanamma Institute of Technology and Science, INDIA) \\ ${ }^{2}$ (Electrical and Electronics Engineering, .G.Narayanamma Institute of Technology and Science, INDIA) \\ ${ }^{3}$ (Electrical and Electronics Engineering, G.Narayanamma Institute of Technology and Science, INDIA)
}

\begin{abstract}
The quick developments in power electronic technology have made it possible to mitigate voltage disturbances in power grid. Among the voltage disturbances challenging the trade, the voltage sags are considered to be the most necessary drawback to the sensitive loads. Dynamic voltage restorer (DVR) is a series connected power electronic based device which will quickly mitigate the voltage sags in the system and restore the load voltage to the pre-fault value. DVR is recognized to be the simplest effective solution to overcome this problem. The first advantage of the DVR is keeping the users always on-line with prime quality constant voltage maintaining the continuity of production. In this paper, the advantage of including DVR in distribution system for the purpose of voltage sag and swell mitigation is interpreted. The DVR presented here is based on the concept of dqo. The control method is found very efficient for identifying and clearing any power quality disturbance in distribution systems. Results of simulation using Matlab/Simulink are shown to prove the importance of this scheme.
\end{abstract}

Keywords: Dynamic Voltage Restorer, Voltage sag, Voltage swell, dqo technique.

\section{Introduction}

Nowadays, Power quality is known as one of the extremely serious problems in electric power transmission and distribution, due to its dangerous impact on electricity suppliers, makers and users. Typically we will outline power quality as the deviation of voltage, current and frequency from its normal values in a power grid [1]. Presently, most of the industries use power electronics conversion and switching for producing and processing. These technologies are in need of prime quality and reliable power supply. Not only the industries, but also the electrical power utilities and customers have become progressively anxious concerning the electrical power quality. Sensitive loads like digital computers, programmable logic controllers (PLC), client electronics and variable frequency motor drives need prime quality power supplies. Good quality of electrical power is important for right functioning of industrial processes as well as protection to the commercial machines and its long usage. The often occurring power quality problems are voltage unbalance, voltage sag and swell, transients, flickers and harmonic distortions. These power quality problems will cause serious malfunctions and lost production in industries [2].

Out of these power quality problems, voltage sag or swell causes a lot of serious problems in power grid, both at transmission and distribution level. Faults on electric power system like short circuit owing to insulation breakdown at heavy load conditions will cause voltage sag. The voltage sag will be defined as decrease in rms value of voltage below the nominal voltage starting from 0.1 to $0.9 \mathrm{pu}$ which lasts for a cycle to 1 minute. Depending on the type of fault, the voltage sag can be either balanced or unbalanced and that they might have magnitudes that cannot be predicted. Voltage swell, in contrast, can be defined as a fast increase in rms voltage above the value starting from 1.1 to $1.8 \mathrm{pu}$ which lasts for a cycle to one minute. Switching off of large loads, energization of capacitor banks etc can be considered as the common causes of voltage swell. Voltage sag occurrence is more common than voltage swell in distribution power grid. Sensitive electronic and electrical equipments may be subjected to failure, complete shutdown or generate a large inrush current that leads to blown fuses and tripped circuit breakers owing to voltage sag and swell. [3].

Out of the various strategies for the compensation of voltage sag and swell, the installation of custom power device in distribution system is considered the foremost accomplished one. The custom Power concept was introduced in the year 1995 by N.G. Hingorani. Flexible AC Transmission Systems (FACTS) deals with various power issues in transmission systems like improvement in power transfer capabilities and stability margins, whereas the custom power devices involves the use of power electronics controllers in a distribution system and deals with various power quality issues and it ensure that the users get a good quality and reliable supply. By good quality, it means: low phase unbalance, less flicker in load voltage, less deformation in load voltage as a result of harmonics, level and extent of overvoltage and undervoltage within desired limits and no power interruptions. Some examples of Custom power devices are as follows: Battery Energy Storage System (BESS), Dynamic Voltage restorer (DVR), Distribution STATic synchronous COMpensator (DSTATCOM), 
Surge Arrester (SA), Super-conducting Magnetic Energy Storage (SMES), Solid-State Transfer switch (SSTS), Static Var Compensator (SVC), Uninterruptible Power Supply (UPS) etc [4].

All of the above mentioned devices have their own benefits and drawbacks. Among the custom power devices, Dynamic Voltage Restorer (DVR) is considered as the most economic and efficient solution for various power quality problems. Some of the reasons for this conclusion are as follows: In comparison with SVC, SVC lacks the active power flow control capability. Therefore DVR is most popular over SVC. In comparison with UPS, UPS is not only expensive but also it needs high battery maintenance and replacement owing to leak. In comparison with SMES, DVR has lower cost and better energy capability. In comparison with DSTATCOM, DVR is smaller in size and lower in cost. Considering these reasons, DVR can be considered as the most effective custom power device for compensation of voltage sag and swell in distribution systems. Additional features of DVR are harmonics and power factor correction. The first DVR installation was in North America in the year 1996 on a 12.47 kilovolt system located in Anderson, South Carolina. Since then and till now, DVRs are useful in distribution systems to safeguard sensitive loads in industries from various power quality problems [5]. In this paper, a quick summary of the DVR, its functions and configurations, its basic elements, modes of operation, voltage compensation strategies and control of the DVR output voltage are reviewed and simulation results using MATLAB are illustrated.

\section{DVR Basics}

A Dynamic Voltage restorer is a recently proposed series connected solid state device that injects missing voltage waveform into the system for regulating the voltage at the load end. Its location in the distribution system is in between supply and load. It regulates the load side voltage continuously just in case of any power quality problems like voltage sag or swell therefore preventing any power interruption to the sensitive load. There are completely different methodologies and control techniques by which a DVR can be implemented. [3].

\section{Principle of operation}

The operation of DVR is based on the fundamental principle that a voltage waveform is injected through an injection transformer that is the difference between pre-sag and sagged voltage. This is often demonstrated in Fig. 1. This is often made possible by the supply of required real/active power from an energy storage device together with reactive power. The turns ratio of injection transformer and ratings of the energy storage device can put limitations on the maximum injection capability of DVR.

Separate control over the magnitude of injected voltage is usually done for a three single phase DVRs.

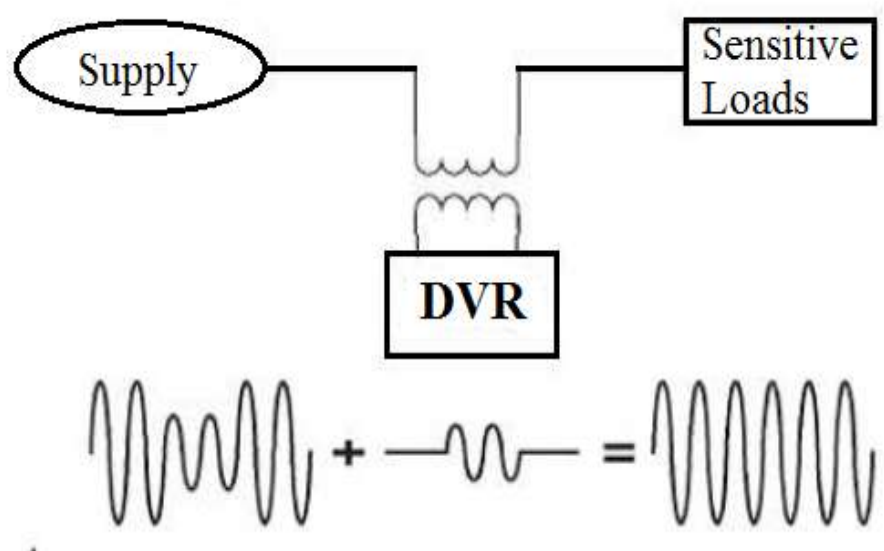

\section{Basic components of DVR}

Fig.1 Operation of DVR

The basic components of DVR are [6]

i. Control system.

ii. DC Energy storage device and charging circuit.

iii. Voltage source inverter (VSI).

iv. Harmonic filter.

v. Injection or Booster transformer. 


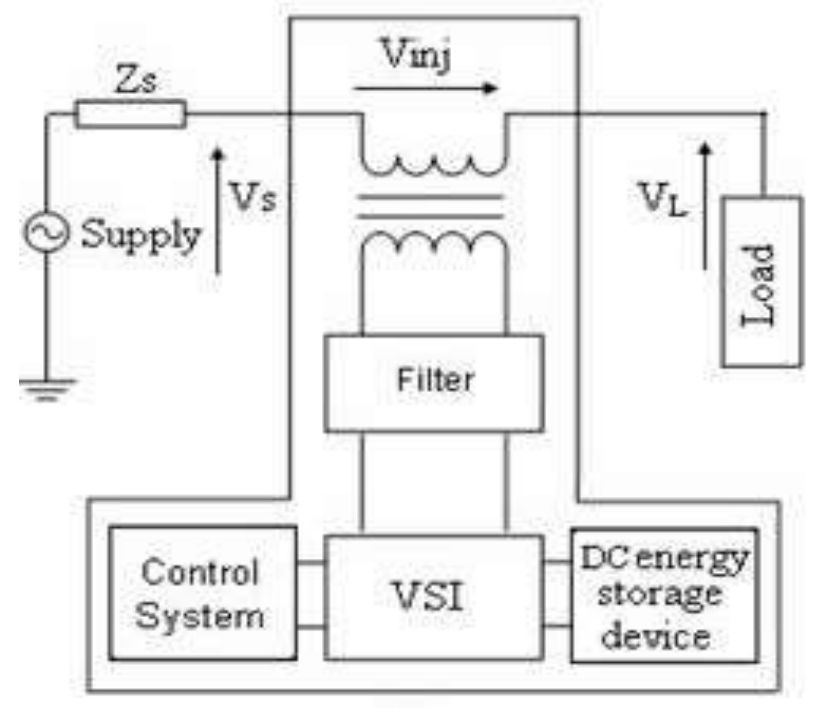

Fig.2 Block diagram of DVR

\section{Equation Related to DVR}

The equivalent circuit of DVR is shown in Fig. 3. On detection of any reduction in the supply voltage, $\mathrm{V}_{\text {source }}$ from any set value, a voltage is injected by DVR, $V_{D V R}$, in series through the injection transformer such that the required load voltage, $\mathrm{V}_{\text {load }}$ will be maintained at the load end.

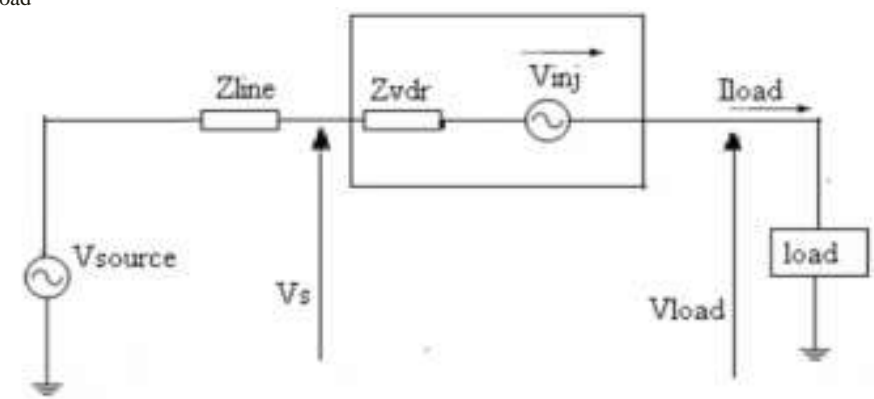

Fig.3 Equivalent circuit of DVR

The DVR injection voltage is as written as in equation (1):

$$
V_{\text {DVR }}=V_{\text {load }}+Z_{\text {line }} I_{\text {load }}-V_{\text {source }}
$$

Where

$$
\begin{array}{ll}
\mathrm{V}_{\text {load }} & =\text { Desired load voltage } \\
\mathrm{Z}_{\text {line }} & =\text { Line impedance } \\
\mathrm{I}_{\text {load }} & =\text { Load current } \\
\mathrm{V}_{\text {source }} & =\text { System voltage during any fault condition } \\
\mathrm{V}_{\text {DVR }} & =\text { DVR injected voltage }
\end{array}
$$

In case if the supply voltage is not sagged or swelled, then the $V_{\text {load }}$ will be equal to $V_{\text {source }}$ and therefore the DVR injected voltage will be a very small amount $\left(Z_{\text {line }} \mathrm{I}_{\text {load }}\right)$ that is needed to compensate for the line voltage drop.

\section{Operating Modes of DVR}

The operating modes of DVR can be classified into three as below:

\subsection{Protection mode:}

In case of high inrush current and short circuit fault on load, the over current on the load side exceeds an allowable limit. Then the DVR will get cut off from the systems by using the bypass switches and providing alternate path for current flow. 


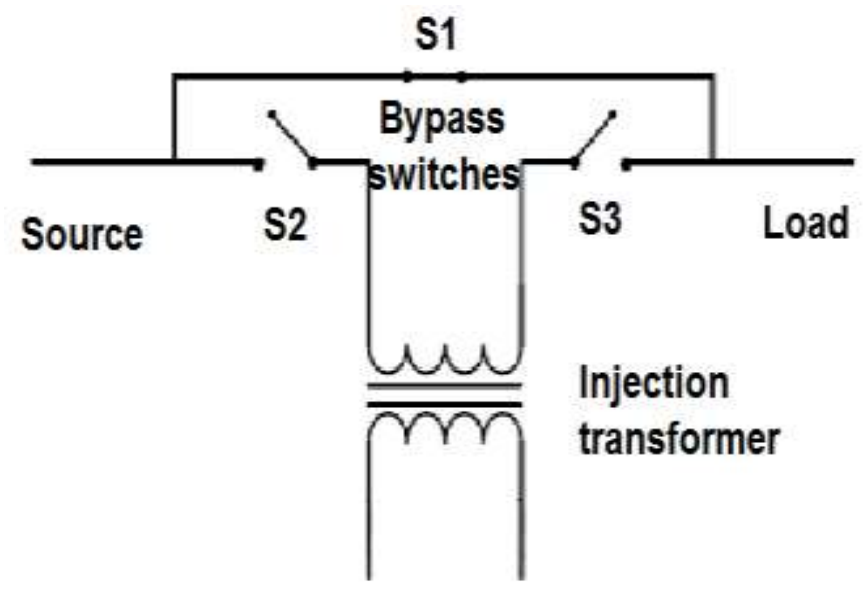

Fig.4 Protection mode

\subsection{Standby mode}

Switching of semiconductors of VSI will not occur during this mode and therefore the full load current can pass through the primary winding of injection transformer. The low voltage winding of the injection transformer is shorted through the converter during this mode.

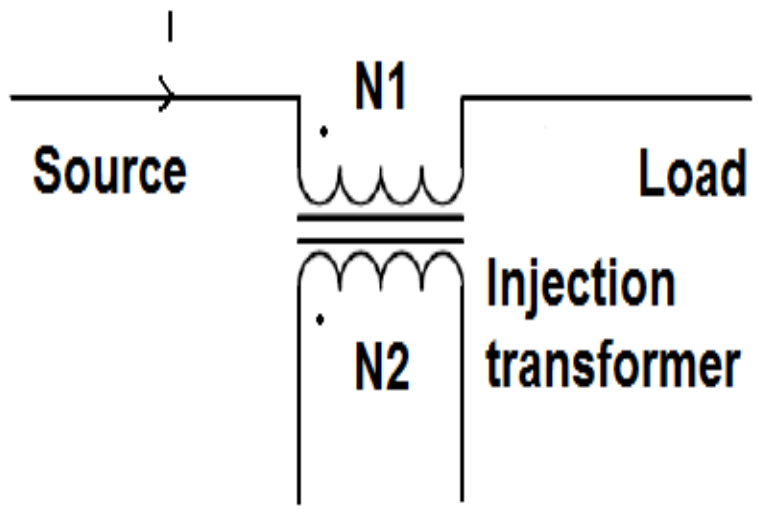

\subsection{Injection mode}

Fig.5 Standby mode

DVR injects voltage through the injection transformer to compensate for any disturbance detected in the supply voltage. [6].

\section{Voltage Compensation strategies of DVR}

Compensation is achieved via real power and reactive power injection. Based on the compensation level required by the load, there are three types of compensation strategies as mentioned below

\subsection{Pre-sag compensation}

Non linear loads need both magnitude as well as phase angle compensation. In pre-sag compensation technique, DVR provides the difference between pre-sag and sag voltage therefore restoring the voltage magnitude as well as the phase angle to that of the pre-sag value. Therefore this method is suited to nonlinear loads. However this method needs a higher rated energy storage device and voltage injection transformers.

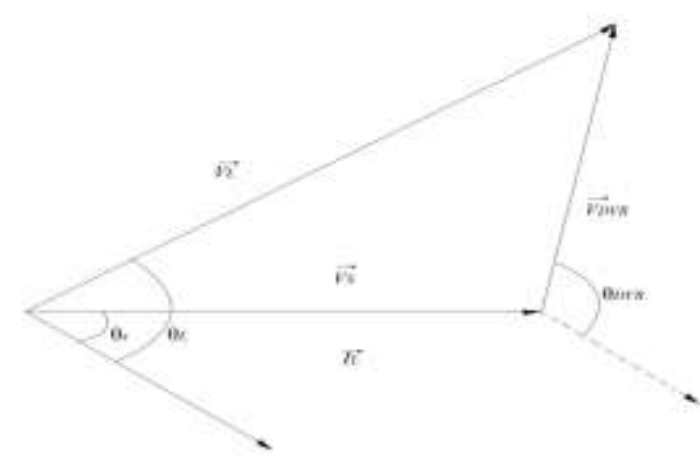

Fig.6 Single-phase vector diagram of the Pre-sag Compensation method 


\subsection{In-Phase compensation}

The DVR compensates only for the voltage magnitude in this particular compensation method, i.e. the compensated voltage has an equivalent phase as that of sagged voltage and it only compensates for the voltage magnitude. So this method minimizes the voltage injected by the DVR. Therefore it is suited for the linear loads, which do not need phase angle compensation.

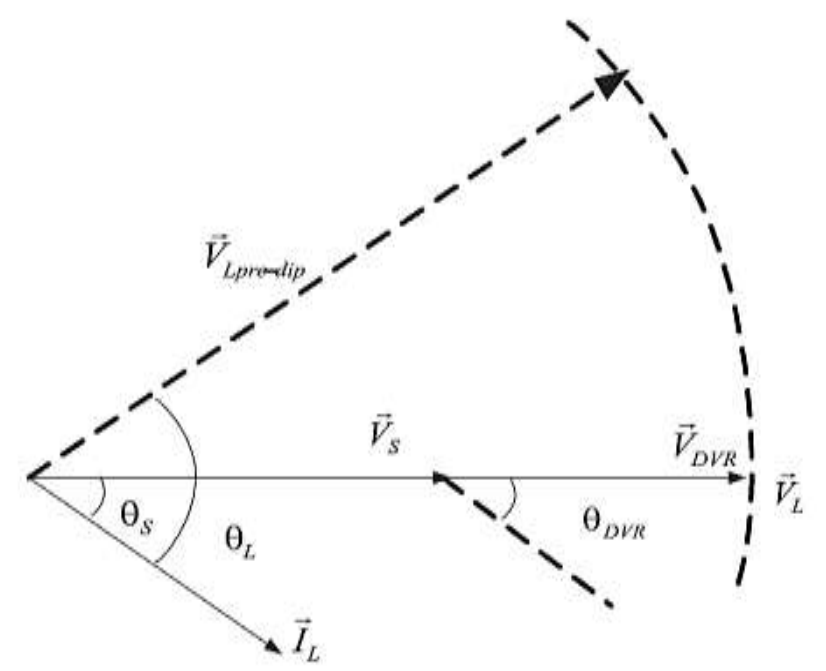

Fig.7 Single-phase vector diagram of the In-Phase Compensation method

\subsection{In-Phase Advanced Compensation Method (IPAC)}

In this technique the real power spent by DVR is minimized by decreasing the power angle between the sag voltage and the load current [10]. In the two previous cases, namely pre-sag and in-phase compensation, active power is injected into the system by the DVR during disturbances. Moreover, the active power supplied is limited to the stored energy in the DC link and this part is one of the most expensive components of the DVR. By creating the injection voltage phasor perpendicular to the load current phasor the minimization of injected energy is achieved. In this technique one can change only the phase of the sag voltage because the values of load current and voltage are fixed in the system $[8,9,10]$. In brief, IPAC technique uses only reactive power and unfortunately, all the sags cannot be mitigated without real power, as a result, this technique is only appropriate for a limited sag range.

\subsection{Voltage Tolerance Method with Minimum Energy Injection}

Generally, the voltage magnitudes between $90 \%$ and $110 \%$ of the nominal voltage and phase angle variations between $5 \%$ and $100 \%$ of the normal state will not disturb the operation characteristics of loads. This technique can maintain the load voltage within the tolerance limits with small change of voltage magnitude as shown in Fig.8 [10]

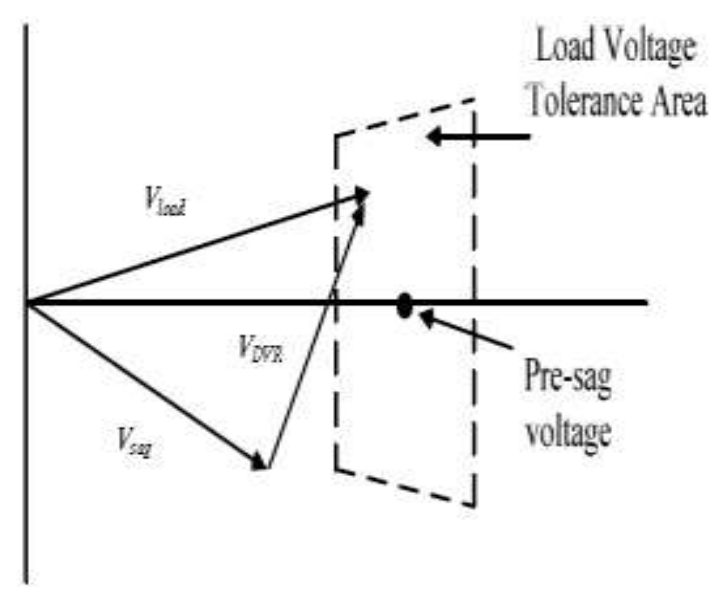

Fig.8 Voltage tolerance method with minimum energy injection 


\subsection{Energy-Optimization technique}

In this specific control technique the utilization of real power is minimized (or made equal to zero) by injecting the desired voltage by the DVR at a $90^{\circ}$ phase to the load current. But in this technique the injected voltage will become higher than that of the in-phase compensation technique. Therefore this method needs a better rated transformer and an inverter, compared with the earlier cases. Further the compensated voltage is equal in magnitude to the pre-sag voltage, but with a phase shift [5].

\section{Proposed Control Scheme}

The control scheme implemented here is with the help of dqo transformation. Once a voltage disturbance occurs, the output of the inverter will be adjusted in phase with the incoming ac supply where as the load voltage is regulated. The output of inverter is provided with inductors and capacitors for filtering purpose. The role of DVR controller is that the recognition of voltage sag/swell problems in the power system; calculation of the compensating voltage, trigger pulse generation for the sinusoidal PWM inverter, correction of any errors in the series voltage injection and extinction of the trigger pulses once the fault is cleared. The simulation block diagram based on the dqo transformation technique is shown in Fig. 9 below.

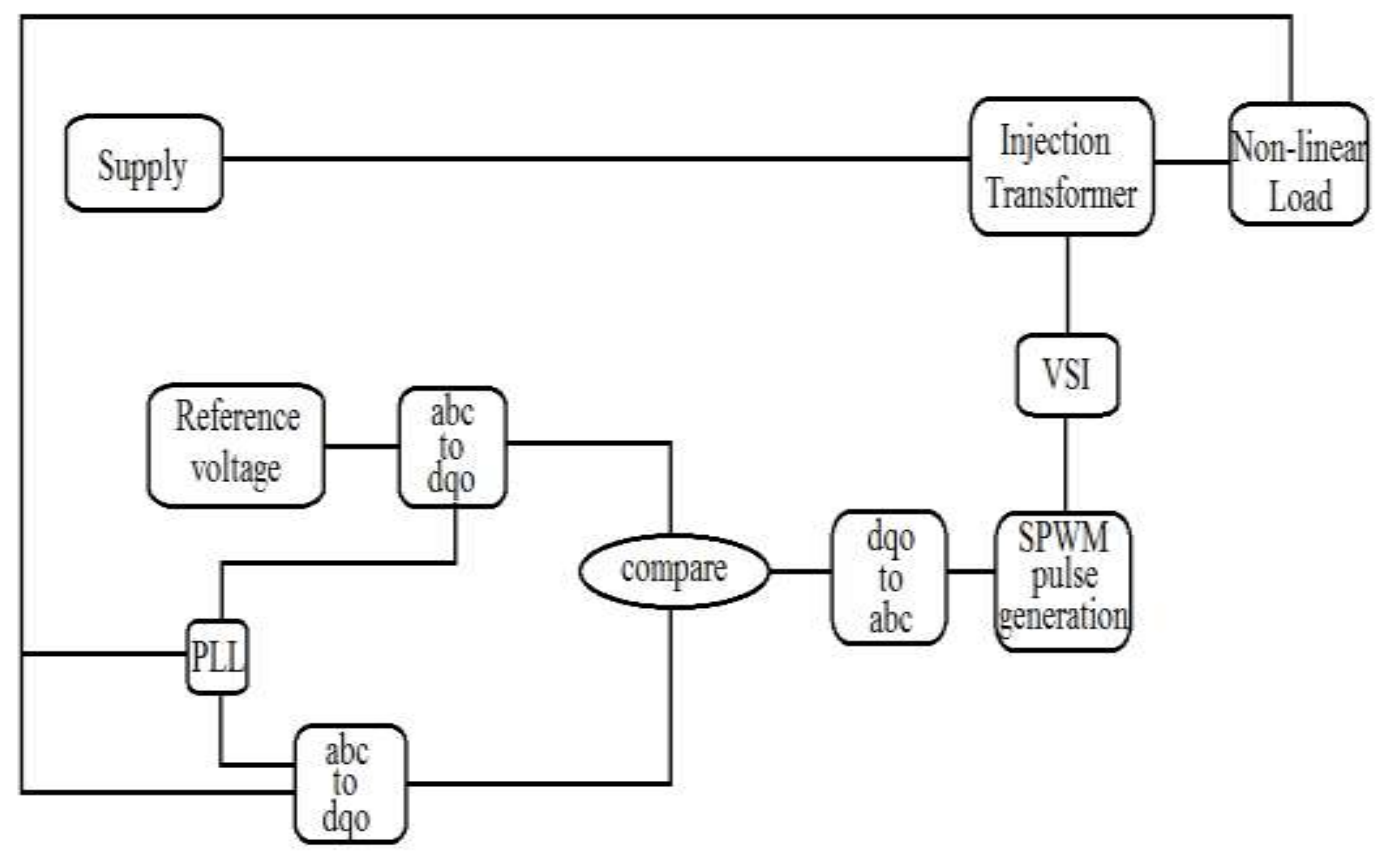

Fig.9 Simulation block diagram

The dqo transformation or otherwise referred to as Park's transformation is implemented here in the DVR controller. The dqo technique provides the magnitude of sag and details of phase shift with their starting and finishing times. The quantities are expressed as the instantaneous space vectors. The voltage is converted from a-b-c reference frame to d-q-o reference. We have a tendency to ignore zero sequence parts for simplicity. The management is enforced by comparing a set reference voltage and also the measured load phase voltage ( $\mathrm{V}_{\mathrm{a}}, \mathrm{V}_{\mathrm{b}}, \mathrm{V}_{\mathrm{c}}$ ).

The error signal formed by the above comparison is used as a control signal that generates a commutation sequence pattern for the power switches of the VSI using sinusoidal Pulse width Modulation technique (SPWM); voltages are controlled by modulation. The PLL (Phase locked Loop) circuit is employed for the generation of a unit sinusoidal wave in phase with mains supply voltage.

A PI controller calculates error value as the difference between a reference value and measured process variable. The duty of PI controller is to reduce the error in outputs by the adjustment of process control inputs. In the figure above it can be seen clearly that two signals SP and PV are being subtracted and their difference is being optimized by the PI controller ahead, whereas SP is the reference set point signal and PV is the measured process variable. The algorithm of PI controller involves two separate constant parameters, and is because of that PI controller can generally call two term control. The two parameters are proportional and the integral values, denoted by $\mathrm{P}$ and $\mathrm{I}$. The $\mathrm{P}$ relies on the present error, and I depends on the accumulation of past errors according to the current rate of change [7].The subjective accumulative value of those two actions is further used to do adjustments in the process through a control element. The definition of the control of proportional feedback is given by the following equation. 
The equation that transforms the three phase a-b-c system to stationary dqo frame is given below equation (2):

$$
\left[\begin{array}{l}
V_{d} \\
V_{q} \\
V_{0}
\end{array}\right]=\left[\begin{array}{ccc}
\cos \theta & \cos \left(\theta-\frac{2 \pi}{3}\right) & 1 \\
-\sin \theta & -\sin \left(\theta-\frac{2 \pi}{3}\right) & 1 \\
1 & 1 & 1 \\
\frac{1}{2} & \frac{1}{2} & \frac{2}{2}
\end{array}\right]\left[\begin{array}{l}
V_{a} \\
V_{b} \\
V_{c}
\end{array}\right]
$$

The direct axis, quadratic axis, and zero sequence quantities for a three-phase sinusoidal signal in a two-axis rotating reference frame is computed by abc to dqo transformation. In this transformation, phase A is aligned with the d-axis which is in quadrature with the q-axis. The angle between phase A and the d-axis is defined as theta $(\theta)$.

\section{Simulation Study And Results}

A detailed simulation of the above DVR system is performed using MATLAB/SIMULINK program to verify its operation under sag and swell conditions. The SIMULINK model is shown in Fig. 10.

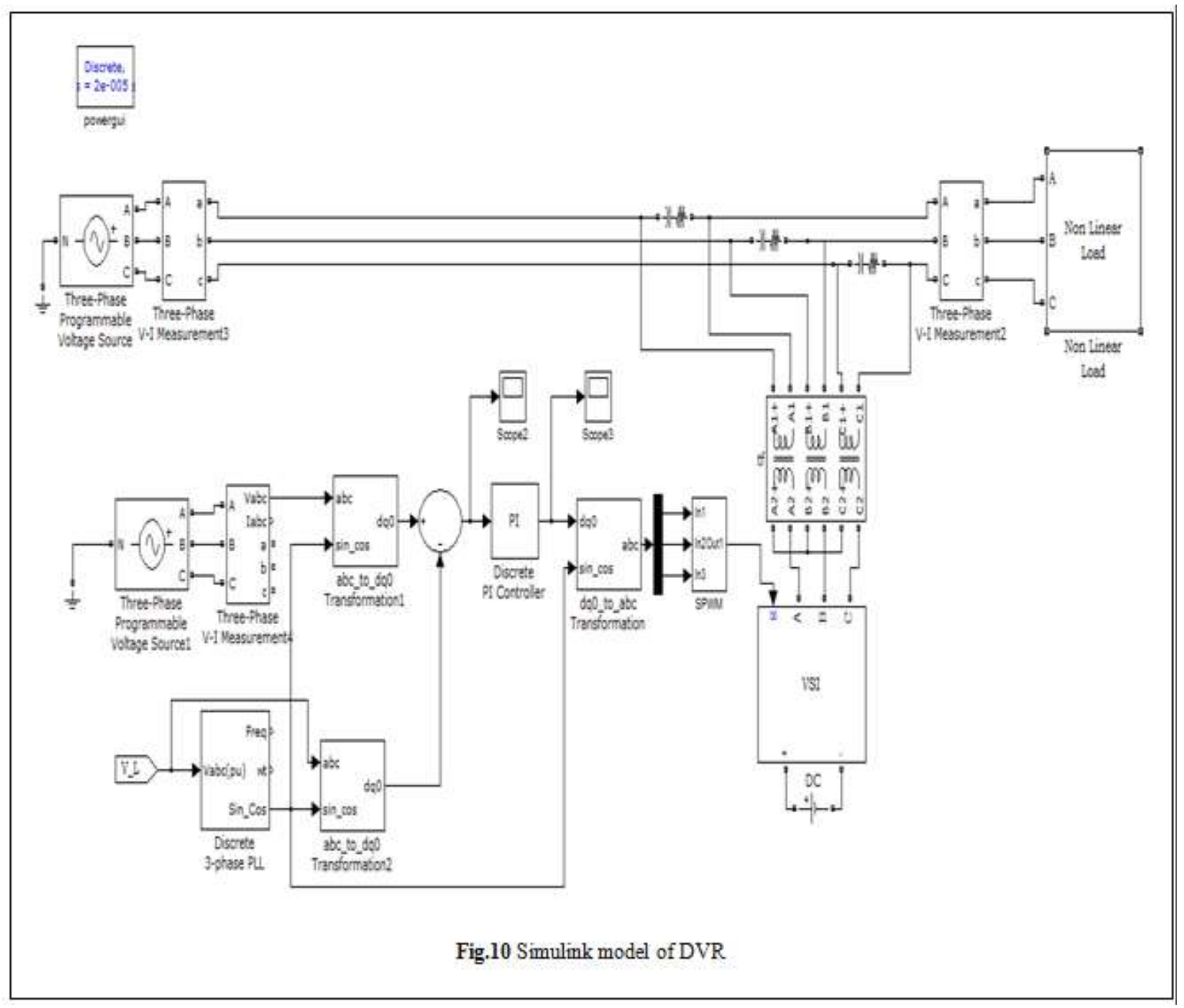


The system data information used in the Simulink model above is listed in Table 1 below.

Table 1. DVR system data

\begin{tabular}{|c|c|}
\hline Supply voltage & $415 \mathrm{~V}, 3 \Phi, 50 \mathrm{~Hz}$ \\
\hline Injection transformer & $1: 1,415 \mathrm{~V} / 415 \mathrm{~V}$ \\
\hline DC link voltage & $600 \mathrm{~V}$ \\
\hline Inverter & IGBT based, 3 arms, 6 pulse \\
\hline PI controller & $\mathrm{K}_{\mathrm{p}}=50, \mathrm{k}_{\mathrm{i}}=50$ \\
\hline
\end{tabular}

\section{Voltage sag}

The simulation results of 50\% three-phase voltage sag in supply voltage is shown in Fig. 11(a). The voltage injected is shown in Fig. 11(b). We may observe satisfactory sag compensation in Fig. 11(c).
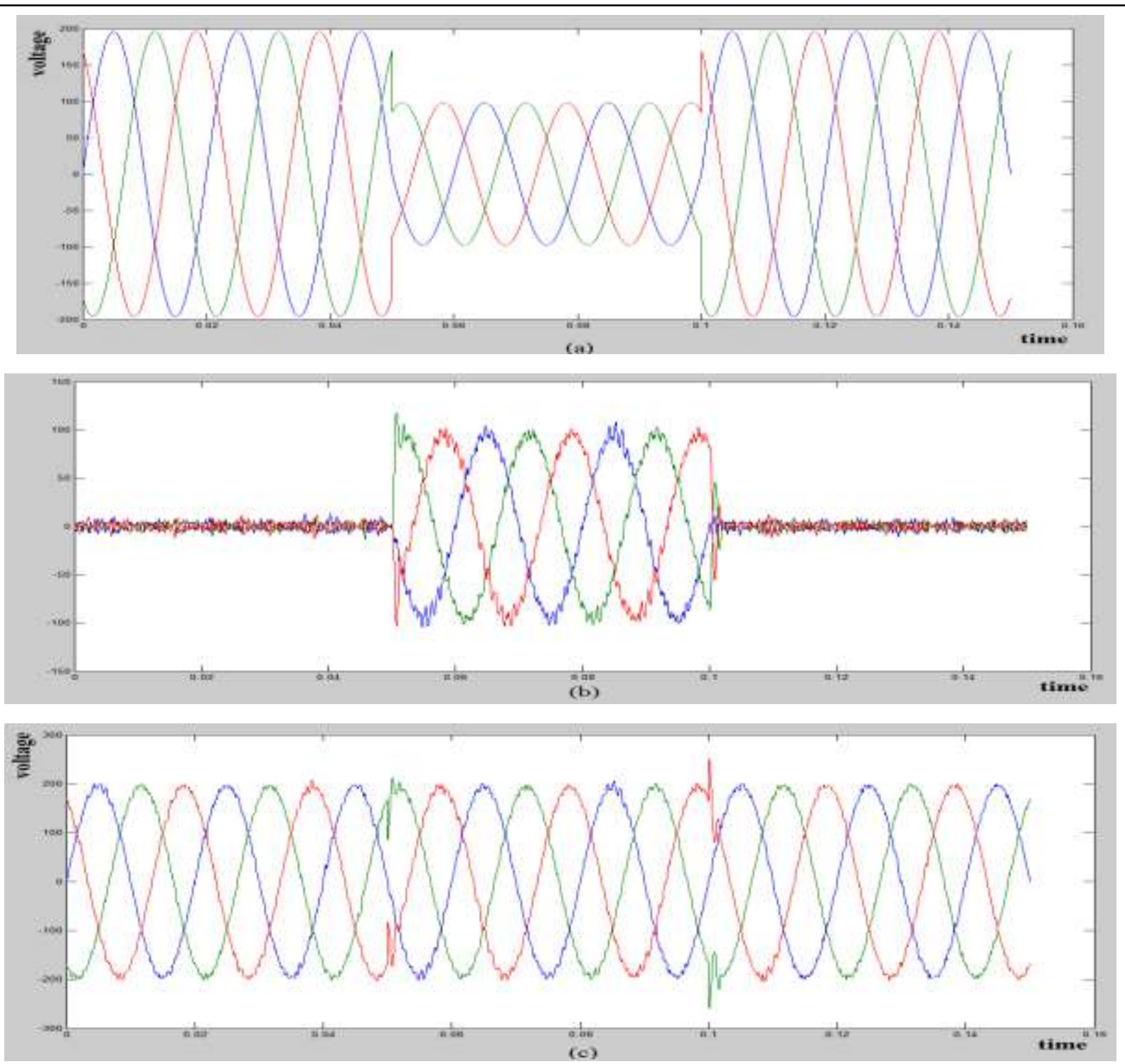

Fig.11 (a) Source voltage with Sag of $0.5 \mathrm{pu}$

(b) Voltage injected by DVR as a response to Sag

(c)Load voltage after compensation 


\section{Voltage swell}

The simulation results of 50\% three-phase voltage swell in supply voltage is shown in Fig. 12(a). The voltage injected is shown in Fig. 12(b). We may observe satisfactory swell compensation in Fig. 12(c).

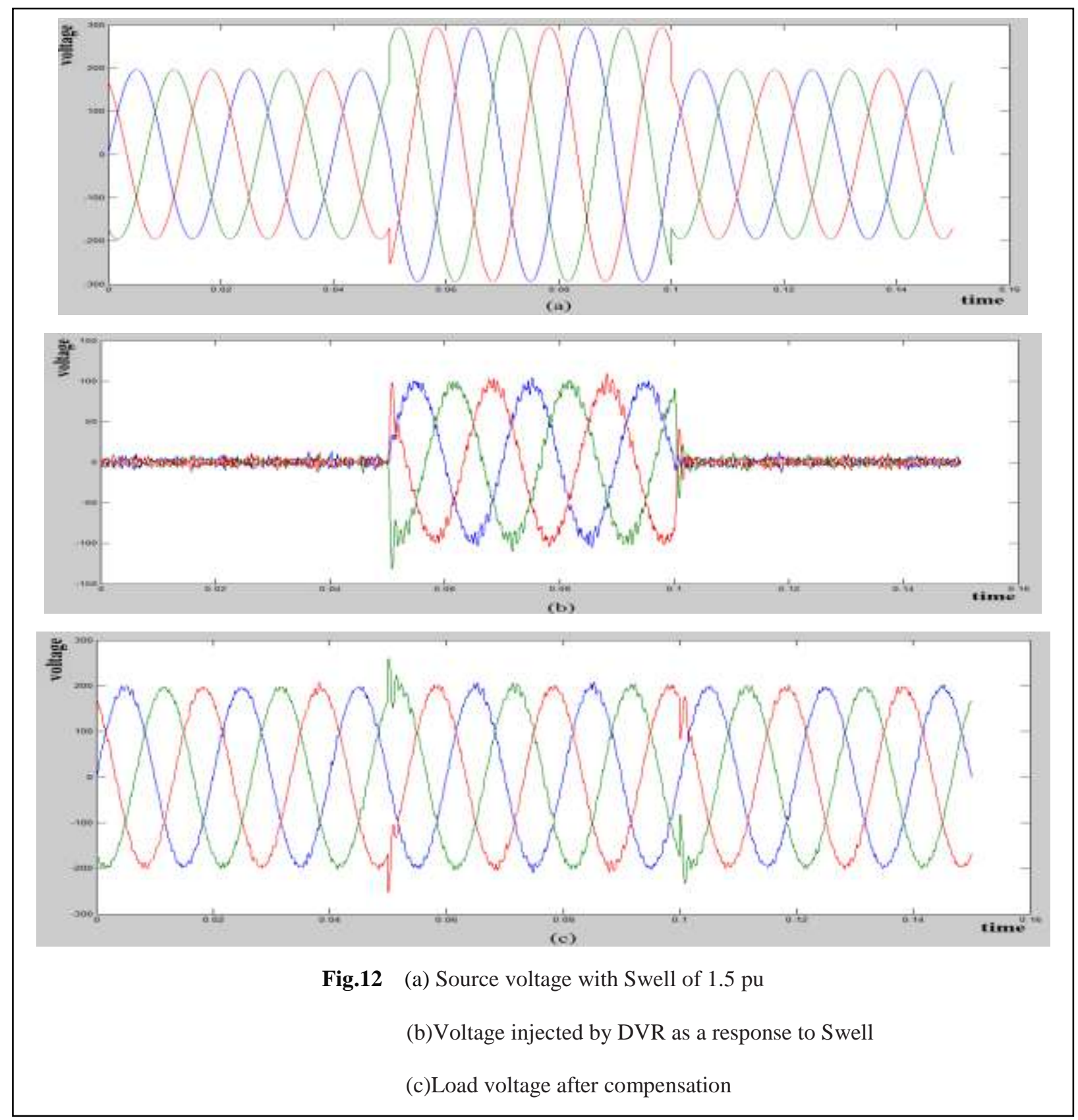

\section{Conclusion}

In this paper, the modelling and simulation of a DVR for $3 \Phi 415 \mathrm{~V}, 50 \mathrm{~Hz}$ distribution system with Sinusoidal PWM based controller has been developed by using Matlab/Simulink. The simulation results show that the DVR compensates the sag and swell and provides excellent voltage regulation. The control system implemented here relies on dqo technique which is a scaled error between supply side of the DVR and its set reference value. 


\section{References}

[1]. Shazly A. Mohammed, Aurelio G. Cerrada, Abdel-Moamen M. A, and B. Hasanin, "Dynamic Voltage Restorer (DVR) System for Compensation of Voltage Sags, State-of-the-Art Review" International Journal Of Computational Engineering Research (ijceronline.com) Vol.3 Issue. 1

[2]. Rohanim Ibrahim, Ahmed M. A. Haidar, Zahim M., Herbert Iu, "The Effect of DVR Location for Enhancing Voltage Sag.” ICIAS 2010: International Conference on Intelligent and Advanced Systems (pp. 1-4). IEEE Xplore: IEEE.

[3]. Chellali Benachaiba, Brahim Ferdi, "Voltage Quality Improvement Using DVR," Electrical Power Quality and Utilisation, Journal Vol. XIV, No. 1, 2008.

[4]. Narain G. Hingorani, Laszlo Gyugyi "Understanding FACTS, Concepts and Technology of Flexible AC Transmission systems"

[5]. S. S. Choi, Member, IEEE, J. D. Li, and D. Mahinda Vilathgamuwa, Senior Member, IEEE, "IEEE Transactions On Power Delivery, Vol. 20, No. 3, July 2005

[6]. Priyanka Kumari, Vijay Kumar Garg, "Simulation of Dynamic Voltage Restorer Using Matlab to Enhance Power Quality in Distribution System”, International Journal of Engineering Research and Applications (IJERA), Vol. 3, Issue 4, Jul-Aug 2013, pp.1436-1441

[7]. Singh, Jai Karan, Mukesh Tiwari, and Dinesh Lodwal. "International Journal Of Engineering Sciences \& Management A Comparative Study Of Tuning Pid By Different Methods." Int. J. of Engg. Sci. \& Mgmt.(IJESM) 2, no. 2 (2012): 148-150. Research and Applications (IJERA), Vol. 3, Issue 4, Jul-Aug 2013, pp.1436-1441

[8]. C. Benachaiba, and B. Ferdi "Voltage quality improvement using DVR", Electrical Power Quality and Utilization, Journal Vol. XIV, No. 1, pp. 39-45, 2008.

[9]. C. Benachaiba, and B. Ferdi "Power quality improvement using DVR", American Journal of Applied Sciences 6 (3): 396-400, 2009.

[10]. M. Tumay, A. Teke, K. C. Bayindir, M. U. Cuma, "Simulation and modeling of a dynamic voltage restorer", Electrical \& Electronics Engineering, pp.1-5, 2006. 